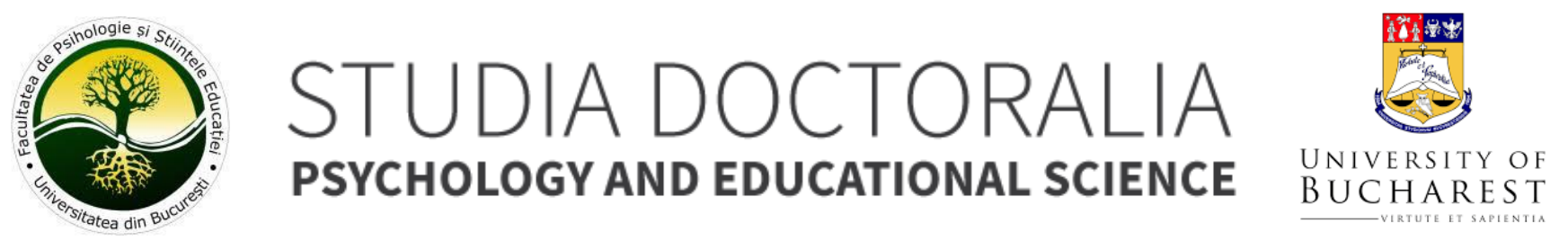

\title{
Community and Sense of Place in an International School Context
}

\section{Dana Lev}

University of Bucharest - Department of Educational Sciences

\section{ARTICLE INFO}

Article history:

Received 04-October-2020

Accepted 28-October-2020

Available online 01-November-2020

This article should be cited as: Lev, D. (2020). Community and Sense of Place in an International School Context. Studia Doctoralia. Psychology and Educational Science, 11(2), 121-131.

https://doi.org/10.47040/sd/sdpsych.v11i2.117

This is an open access article under the CC BY license (http://creativecommons.org/licenses/by/4.0/).

Corresponding author at: University of Bucharest, Department of Psychology, 90 Panduri Av, Bucharest, RO. Tel.: +40 (0) 31-425.34.45.

E-mail address: danale31@gmail.com

\section{ABSTRACT}

This study seeks to identify and explore the sense of place that Third Culture Kids (TCKs) have and the various interpretations that TCKs have regarding their lived reality, as they form part of the international community in Romania. This study contextually explores the sense of belonging to a place. The purpose of the study is to ascertain the role and ways of implementing "Place Based Education" in the context of international and multicultural education systems that serve TCK populations. This was done while trying to understand concepts from the expatriate way of life as expressed by TCKs who attend the American International School of Bucharest. Two main assumptions form the grounds of this study: When an international school combines an International Baccalaureate (IB) system with Place Based Education (PBE) criteria, would it contribute in creating a "Sense of Place" towards the school and contribute in creating a positive foreigner self-identification? This research aims to understand whether and how PBE can be implemented in an international school. Throughout two academic school years, field observations and interviews with students and school staff were conducted. The data analysis resulted in three main findings. The first finding was ambivalent feelings towards the host country that were connected to expressions of place attachment, place dependence and place identity. The second finding was self-identification as a TCK and a sense of belonging to an international community. The third and most surprising finding was a strong sense of place in relation to the school. This process led to comparing Place Based Education criteria to the criteria of the International Baccalaureate program and discovering that these two pedagogical worlds are overlapping and can therefore be easily combined.

Keywords: sense of place, self-identification, school 


\section{INTRODUCTION}

\section{Globalization and Expatriation}

According to Orr (1992) in the United States people relocate an average of ten times during the course of their lives. Bauman called it "Nomads" - individuals that spend most of their lives on the move and do not spend a significant period of time in a specific place. Bauman extended the definition of a "Nomad" to one that does not have a psychological commitment to a specific country. As the mediums of Internet and television take a bigger place in our lives, natural borders are becoming metaphorical, and individuals are no longer bound to them (1988). According to the International Migration Report of the United Nations (UN), as of 2017 around 258 million people have moved and are living in a country that is not their country of birth, meaning that $3.4 \%$ of the world populations are considered to be international migrants, with a consistent increase of $5.4 \%$ migrational moves since the 2000 report. $64 \%$ of the migrants in the past decade moved to high income countries (UN DESA Migration Report, 2017).

The new global world, which enables individuals to travel often or live on the move, is seen as a fluid place that is missing a sense of union between individuals or communities. This process is a result of the world losing its center core of unification and the dissolution of the society (Bauman, 1998).

Research that analyzed over 1,500 articles about expatriates came to the conclusion that there is not any agreed upon academic definition of the word "expatriate". The term "expatriation" emerged from the moment countries first existed and people traveled around the earth. Historical evidence for trade and journeys exists from two millennia back: goods traded by merchants, church missioners sent on religious journeys or emissaries sent by kings to explore other continents on economic or diplomatic causes. Since ancient times, people have been traveling from country to country, continent to continent. "Expatriation" means out of the country, as in Latin: "ex-patria." McNulty \& Brewster (2017) searched the United States Library of Congress (n.d.) and found evidence from the 17th century for "pioneers" being referred to as expatriates. Most of these pioneers were individuals that moved from one country to the other because they were expelled, exiled or deprived from their citizenship, having no possibility of returning to their countries. McNulty \& Brewster presented evidence from work by Marrus (1985), showing that passport manufacturing was already in process and being used during the First World War (2017).

The modern informal definition of expatriates comes from the business employment area and refers to individuals that are sent temporarily to work abroad by the organization at which they are employed (Andresen et al., 2014). McNulty \& Brewster define business expatriates as: "legally working individuals who reside temporarily in a country of which they are not a citizen in order to accomplish a career-related goal, being relocated abroad either by an organization, by selfinitiation or directly employed within the host-country" (2017, p.32).

Many Individuals move from country to country for economic or career reasons. The UN DESA Migration Report (2017) showed that most of the international migrants until that year were of working age $(74 \%)$, a fact that affects the host country's economy. It contributes to population growth and lowers the number of people in nonworking ages that are economically dependent on others (elders and kids). The report states that the largest groups of migrants live in the United States (almost 50 million people), Saudi Arabia (12 million), Germany (12 million), the Russian Federation (12 million) and the United Kingdom (9 million). About half of the migrants were women, and in almost all the countries, female migration exceeded that of male. Looking at the global wave of migrants, statistics show that only $10 \%$ are asylum seekers and refugees. The vast majority of the refugees move to low- or middle-income countries (UN DESA Migration Report, 2017). According to Schwartz, Montgomery \& Briones, expatriates are a minority group in their host country. They described them as a unique minority group, a powerful minority from a high socioeconomic level. Unlike the other minority groups around the world, expatriates can afford a high level quality of life and daily access to private exclusive infrastructure in the fields of education, health, and banking. (2006).

\section{International schools}

The "International School Consultancy" (ISC) presented this definition for an international school: "a school that delivers a curriculum to any combination of pre-school, primary or secondary students, wholly or partly in English outside an English-speaking country, or offers an English medium curriculum other than the country's national curriculum and is international in its orientation" (ISC, 2015).

Due to global economic behavior and the global changes in mobility of workers, the number of people moving from country to country, not in an attempt to emigrate, is growing each year. In most cases, the children of these people attend what is known as: "International schools". These schools, on their part, adapt themselves to the different needs of this population and are in constant growth.

International schools originally developed as a way for expatriate workers to educate their children while following geographically mobile careers. Their original targeted public was foreign students. At the beginning of the globalized area - the late 19th century, people started asking for an educational system that would allow their kids to experience a continuous feeling while moving between countries and at 
the same time to be able to study in a recognized and certified curriculum. In 1855 an international school opened in Hong Kong, which was a British colony at the time, with kids from 100 different countries (Bray \& Yamato, 2003). Ten years later, an international school was opened in London, England, as a response to dissatisfaction that had emerged with the public education system there (Sylvester, 2002).

"International school" is a name that embraces numerous and varied systems of private fee paid education. The private education sector holds a high status and exclusive prestige. Adding to this status is the fact that many of the teachers working in these schools have a higher education than local teachers do and are expatriates themselves (Halic et al., 2014). International schools are not all the same; the student population attending them depends on the host country's permission for locals to attend the international system or not. International schools also differ from each other by their curriculum and certification (Hayden, 2008). Pollock \& Van Reken described international school structure and core: International schools are mostly run in English as their main language, since the students attending them speak many languages. These schools' populations can be so varied that they will host students from 40-60 different nationalities. One of the main challenges of an International school is coping with a consistent transition, sometimes more than a 30\% turnover of school staff and students, every year and even during the school year (2009). At the same time, and as a result of economic and business movements, there is a huge increase in the number of international schools all over the world (ICEF Monitor, 2014). The current study in this paper explores the American International School of Bucharest (AISB) which bases its curriculum on the International Baccalaureate (IB) program.

\section{International Baccalaureate Program}

According to the International Baccalaureate Organization (IBO), the IB program was initiated in its first version in 1968, offering a Diploma Program for kids that belong to the international nomad community. The program aimed to enable geographic mobility and a culturally open state of mind, creating the academic conditions for recognition and qualification for universities across the world.

The IB setting is focused on global aspects with the purpose of promoting compassion, tolerance, respect, activism and intercultural understanding, while developing challenging programs that will produce lifelong learners with environmental awareness and international-mindedness. IB education places the student at the center, defining the IB learner profile as one that has these ten attributes: $A$ thinker and knowledgeable, communicator and open-minded, risktaker and principled, inquirer and reflective, caring and balanced. "The International Baccalaureate aims to develop inquiring, knowledgeable and caring young people who help to create a better and more peaceful world through intercultural understanding and respect" (IBO, "Mission", n.d.).

A crucial part of the IB program is continuing rigorous assessment procedures. Assessment is recognized as a central process, meaningful in supporting the achievement of curricular goals. The IB assessment process is constructed of a variety of strategies and methods; it is an ongoing process fundamental to the success of the curriculum. One of the projections of this process is providing students with cognitive and empirical tools to selfassess their work and others, believing that students benefit from analyzing data and understanding it.

The IB program uses teaching methods that emphasize individual research, autodidactic techniques and projectbased learning methodologies. It aims to prepare the students for the new globalized and changing world, to be able to live and work in a perpetually developing reality. It encourages students to explore and develop their intellect and socio-emotional skills to be able to understand and analyze situations that contain local, national and international issues (IBO, "Teaching," n.d.).

\section{Third Culture Kids}

International schools were originally opened in order to provide a stable though mobile educational framework for kids from families that have a mobile lifestyle, and most of these kids can be referred to as Third Culture Kids (TCKs). These schools' objective was to provide the TCK students a stable academic ground that would prepare them for the day they repatriated to their passport country, sothis meant providing private education in the language of the passport countries (Hayden, 2011).

Third Culture Kid is a term referring to kids that spend a significant amount of time during the stage of their developmental years outside of their parents' country of origin and culture. According to Pollock \& Van Reken, TCKs find themselves building all kinds of relationships in all the cultures they are exposed to, even if they don't feel that they are part of that culture. It seems that elements from each culture are assimilated into the TCK's life experience, but developing a feeling that they belong depends on their relationship with others. TCKs might express an identification to several cultures at the same time, or to none, and a sense of belonging with other TCKs that experienced the same mobile lifestyle (2009).

The term TCK was first mentioned in the 1950s by Ruth and John Useem (1999) and described the three cultures that American children were exposed to while living in India. The United States was the country of origin of the parents and was referred to as the first culture. India was the host country and was referred to as the second culture. Between 
these two cultures, and as a result of the non-migrant lives these kids were having, they defined the nomadic culture as the third culture.

Schaetti (1993) wrote quite a similar definition for the term "Global Nomads": these are individuals that, as a result of their parents' career mobility, lived in one or two countries outside of their home or passport country during their developmental period of life. They are considered to have a unique cultural heritage, having gained elements from all the cultures they got to know into their identity and express a sense of belonging to all the cultures they observed.

An expat community is a temporary community of expatriates from around the world who surround and enrich themselves with American and British international schools, recreational clubs, commissaries, and other community nomadic centers that help the third culture blossom. Pollock \& Van Reken (2009) now use the TCK term to include individuals from any country who have spent significant time during their developmental formative years in second and third cultures other than their parents' culture of origin. Often, the parents are diplomats, military personnel, missionaries, teachers, or working in international business. They are different from immigrant kids who plan to stay in the host country permanently. TCKs are living "on the move", having plans to repatriate again or go back to their original country; many of them are offspring of parents from different countries and cultures (Pollock \& Van Reken, 2009).

TCKs are different from immigrants in the fact that TCKs rarely try to become citizens of the second culture. TCKs hold passports to the countries of their first culture and fully expect to return (often when they are 18). Psychological research on TCK populations is sparse. Research on the children of military families posted abroad and children with international school experience seem the most prevalent (Gerner et al., 1992). The majority of research into international school students has focused on the experiences of the so-called TCKs or Global Nomads (Pollock \& Van Reken, 2009; Grimshaw \& Sears, 2008) that is, students who are living and studying outside their parents' culture. The issues of self-identity that have been addressed by such research are related to the life-style of many of these children who often move house and cultures throughout their schooling, thereby experiencing repeated dislocations (Ezra, 2003) and disjointed narratives of identity (Grimshaw \& Sears, 2008).

\section{Place Based Education}

While International education is expanding all over the world, allowing students to get a global education, at the same time a different, micro-focused local educational approach is gaining popularity. Local schools around the globe are looking into their curriculum and having an educational discourse that changes and empowers the connection of the educational process to the place and local community by giving them a bigger emphasis. This approach can be seen in various countries; schools in the United States, Australia, Asia and all over Europe are breaking the pedagogic routine and starting to step out of the classroom and change formal educational concepts. They are creating learning methods connected to the outdoors, nature, local community and parents' community ("What is," 2017).

The concept of "place" was divided into three dimensions: place identity, place attachment and place dependence. These three place dimensions constantly appear in literature regarding environmental psychology (Jorgensen \& Stedman, 2006). The three Place Dimensions: Place Identity, Place Attachment and Place Dependence were gathered by Shamai (1991) under the title "Sense of Place".

Place attachment was defined as positive feelings towards an individual's private place, such as his property (Moore \& Graefe,1994). Williams (2014) offers a definition that looks into the type of bonding the individual has to the place: a bonding with an emotional or functional meaning. Place dependence refers to the importance and meaning of a place for a specific functional activity which creates a functional attachment. In order to identify themselves from others, individuals give importance to activities and objects, just as they give importance to places (Williams, 2014). Place identity was defined by Proshansky, Fabian \& Kaminoff as the amount of importance the individual gives to a place, or the symbolic meaning the place has in the eyes of the individual. Place identity is the representation of the individual's relation and beliefs towards a certain place, such as a lakeshore or city park (1983).

Place Based Education (PBE) is an educational belief that can be combined with all types of curriculum, in any kind of school, located anywhere in the world. It is an educational platform based on the idea of community involvement, connection to nature and outdoor pedagogical methods, while using local concepts and a variety of local resources. Sobel defined it as a process of using the environment and community as a fundamental base for teaching different educational concepts across the school curriculum. In Sobel's eyes, experiencing direct practical "real-world" activities increases academic achievements. It is a longterm educational process that enhances community vitality, empowers community organizations, honors nature, and creates active, caring citizens (2005). It is a deep learning model considered to have a high impact on both students and educators, since educators using a PBE learning model also engage with different groups included in the school community, such as parents, family members, school staff and, of course, students. They (educators) tend to encourage connections and partnerships between school and local resources, such as NGOs, cultural institutions, 
natural resorts, business and more ("Quick Start," 2017). In order to transmit a "Place" as a meaningful tool for education, every school should combine in its curriculum a variety of ways to connect to the community and to mirror the society outside. Schools should be built as a small model of the real world (Dewey, 1897 in Orr, 2013).

\section{PBE and Community}

Research shows that highly attached people have a high probability to unite together in order to achieve a common challenge or purpose and show pro-environmentally responsible behavior (Brown et al., 2002). In the process of analyzing place attachment effects, Anton \& Lawrence, criticized the efficiency of measuring bonds between individuals and their friends with whom they share environments. They suggested, instead, restricting the research on the bonds to a physical place, such as a home or a park with clear borders (2014). The colleagues and friends with whom individuals share environments can be referred to as community attachment (Trentelman, 2009).

An educational system that integrates the learning process within the close society is likely to function as a stable, democratic and well-informed base for the community. PBE can be implemented anywhere and any

\section{METHODOLOGY}

The purpose of the study was to check the role and ways of implementing PBE in the context of international and multicultural education systems with TCK as students. This study tried to understand where international education meets place-based theories. Are they parallel worlds, overlapping, or do they intersect at a peak point during the student's years of formal education? This research aspired to develop awareness of the existence of the TCK population in Romania and in the world, and stimulate interest among the Ministry of Education as the formal educational representative structure of the host country. The first assumption of the study was that the IB system combined with PBE criterias as implemented in the American International School of Bucharest contributed in creating a "Sense of Place" towards the school. The second assumption of the study was that the IB system combined with PBE criterias as implemented in the American International School of Bucharest contributed to creating a positive sense of "foreigner identity" in TCKs. The fundamental paradigm that was used in this research was a qualitative method. The data collection in this research was done through interviews, field observations and text analysis. Semi-structured interviews were conducted with school students and key staff members of the AISB. The interviews were based on a questionnaire with open-ended questions, and took place on school campus territory, lasting time. It can incorporate the local sites or attractions of the place to create a personalized learning process. As personalized learning is increased, students can profit from applying knowledge, and communities profit from direct contact with the students, young curious adults eager to improve the community ("Quick Start," 2017).

The study reported in this paper addressed a number of important questions which very much need answers. By studying the sense of place perspectives of TCKs attending an international school, this study aimed to gain a clearer understanding of the needs and aspirations of international schools' faculty teams. At the same time it raised issues relevant to the parents of TCKs and their educational aspirations. Another possible extension of this study is to raise issues relevant to local education authorities and their policy planning concerning students attending international schools. Additionally, the findings of this research could have relevance to international expatriate communities around the world or Parent Teacher Organizations (PTO) which hold a meaningful role in encouraging educational issues related to social cohesion.

15-20 minutes. The operational methodology was subject analysis through central themes and patterns identification.

The interviews with the students were conducted in order to explore expressions of the three place dimensions: Place attachment, Place identity and Place dependence, all together known as "Sense of Place". Open questions were made in order to allow the interviewees to express themselves freely without unconscious connections to expected answers. Field observations took place on school campus during routine school days, community events on school campus and in outdoor activities of the secondary school during the experimental week. All the observations were made during the school years 2018-2020. Twenty-two validated interviews were conducted on 22 middle and high school students attending AISB that were between 12 and17 years old. All students were living in Bucharest, Romania for more than 3 years. None of the students has a Romanian speaker parent, and none of the students speaks Romanian language at a mother tongue level. Parents' place of birth varied: Bulgaria, Italy, Israel, Mexico, Pakistan, South Korea, Spain, Turkey, USA, Venezuela, Germany, Greece. In $50 \%$ of the families, one of the main languages spoken at home is English, either with the parents or with siblings.

This age group was chosen based on the assumption that children of these ages, at secondary school, are mature enough to conduct a continuous, focused and practical discussion. They are able to recall past 
experiences, compare present experiences and imagine the future. However, they are still completely in the adolescence stage and their peer group, as important as it is, is still secondary to the influence that comes from home. McNeely \& Blanchard showed that building a sense of self involves the adolescent brain allowing teenagers to begin with the process of building their sense of self, as part of their personal identity, by giving them the cognitive tools to do that. Self-esteem and self- concept combine together to create one's sense of self. During these years, teenagers develop their social awareness; they learn to be aware of their body and mind to understand what they are feeling and to be able to give that emotion a name (2009). The semistructured interviews contained six questions that represent the three place dimensions of "Sense of Place": Place identity, Place attachment and Place dependence, based on Jorgensen \& Stedman's research on lakeshore property owners, their feelings and sense of place towards the lake and property they own (2006). The questions were meant to give a structure to the conversation that would allow the participants to talk freely about their feelings towards the place without being guided or led into certain expected expressions.

The questions that were asked:

1. If you were asked to explain to other people, what does it mean to live in Bucharest, what would you say?

2. If you were asked to explain to other people, what does it feel like to live in Bucharest, what would you say?

3. What are your hobbies, and where do you practice them?

4. In your opinion, what is a home?

5. If you were asked to close your eyes and think of anywhere in the world.... Where would be the place that you feel most comfortable?

6. If our world could be described by a circle diagram, we would put AISB in the middle, Pipera (the schools' neighborhood) around it, Bucharest around Pipera and Romania as the biggest circle.

Would you say there is a relationship between these circles? Can you explain it to me?

\section{RESULTS}

Findings from students' interviews showed ambivalent feelings towards the host country.

\section{Place attachment}

There were markedly more negative feelings expressed towards Romania, the host country (37 quotations), than positive feelings towards Romania (32 quotations). At the same time, both negative and positive feelings towards the host country were repeatedly expressed and fully present

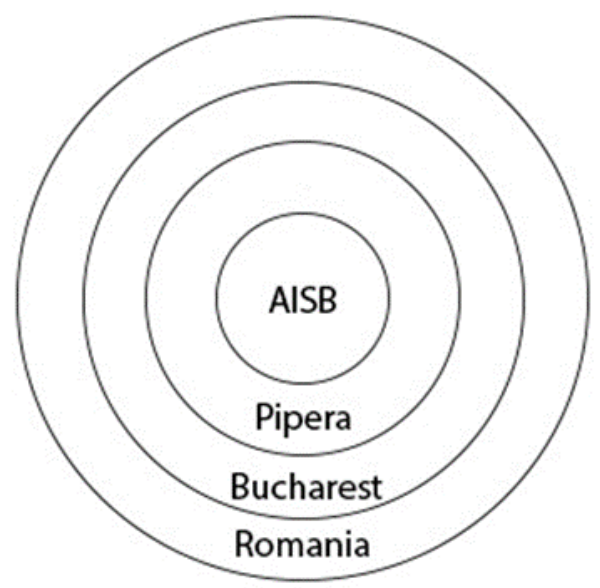

Figure 1. Representations of the three place dimensions

Representations of the three place dimensions were seen and detected in the answers to each one of the questions through phrases such as the following:

Representations of Place identity were assumed to look like these sentences:

Everything about is a reflection of me says very little about who I am

I feel that I can really be myself at reflects the type of person I am

Representations of Place attachment were assumed to look like these sentences:

I feel relaxed when I'm at

I feel happiest when I'm at is my favorite place to be

I really miss __ when I'm away from it for too long

Representations of Place dependence were assumed to look like these sentences:

is the best place for doing the things that I enjoy most

For doing the things that I enjoy most, no other place can compare to

to do

is not a good place to do the things I most like

As far as I am concerned, there are better places to be than

throughout the interviews. Both negative and positive feelings towards the host country were expressed when answering different questions regarding different matters (practicing hobbies, life in Romania, etc), meaning that the host country is present in TCKs emotional bond and personal interpretation of their lived reality and emotional connection in an ambivalent way.

Hay (1998) showed that permanent residents reported more feelings of attachment than their peers that are not permanent. Individuals that rent houses instead of own 
them, or individuals that plan a future move, reported less attachment to the place. One can assume that, as a result of the TCKs' mobile lifestyle, they assume a future move is a legitimate option and let that assumption interfere with them being fully attached to the host country. Tulving wrote that learning from past experiences is a fundamental necessity in creating a solid sense of self (1985). Schacter \& Addis added that planning future moves is based on remembering past experiences (2007).

\section{Place dependence}

A similar ambivalent expression was found when looking for themes regarding expressions of "sense of dependence". Fifteen quotations were marked regarding sense of dependence to the host country, and 11 quotations were marked regarding sense of dependence to AISB, the school. There were more expressions of dependence toward the host country than dependence towards the school although the difference was small. This could mean that being dependent on expressing your passions, practicing your hobbies and expressing yourself is not bound only to the possibilities offered by the host country but also to the options offered to the students by the school they attend.

\section{Place identity}

A sense of place identity was detected throughout answers to several questions during the interviews. The answers showed a consistent expression of the students perceiving themselves as part of a group, being part of something bigger than the individual. The students saw themselves as members of an international nomadic community and felt a sense of belonging to such a group. Thirty-three quotations were marked as referring to recognition and/or identification with a community, and 33 quotations were marked as identifying with a foreign identity and referring to being a TCK.

\section{Sense of place towards the school}

The most surprising finding and, therefore, most central was the repeated expressions that represent the international school as a main and meaningful element in the TCK students' lives. A collective narrative was detected in the group of TCK students attending AISB, showing a sense of place towards the school. Twenty quotations were marked as positive feelings towards the school itself, meaning TCK students sense attachment towards AISB, the international school that they attend in the host country. In fact, only two respondents didn't express a sense of place attachment to the school. This finding was surprising since it was expected

\section{DISCUSSION}

Place Based Education Versus International Baccalaureate. The core of the IB program is being international: providing international education to kids that have a mobile lifestyle and belong to the global nomad to find sentiments of place attachment towards the host country.

While planning the research, the school was not taken into consideration as the "Place" that the TCK students would express attachment to since most research about TCKs relates to their cross cultural experience in the passport country or host country (Cottrell, 2009). When the interviewed students talked about feeling part of a community, a group narrative was detected regarding an international community that consists of the school community that lives in the school surroundings (Pipera neighborhood). This makes sense when looking into the process of analyzing place attachment effects. Anton \& Lawrence criticized the efficiency of measuring bonds between individuals and their friends with whom they share environments. They suggested restricting the research to bonds to a physical place, such as a home or a park with clear borders (2014). The colleagues and friends with whom individuals share environments can be referred to as community attachment (Trentelman, 2009).

The original assumption of the research focused on the host country as the "place" of reflection, as the "place" to be attached to, identified with and depended on. As the interviews went on, it became clearer that the students identified themselves as part of the school community and were attached to the school. Therefore, the "place" the research focused on was changed to the school.

The desire to be part of a group, the desire to feel that you belong, is a basic psychological need. Osterman reflects about the fact that many schools, while being a meaningful social organization in students' lives, don't necessarily approach and support the students in the actual process of creating this feeling and experiencing belongingness. Her findings show that school policy and staff norms might undermine the importance of creating community in school that will make students feel that they belong. In fact, schools might neglect it in practice (2000).

In this current research, in order to get a profound understanding of AISB's community, different aspects were revised: the school vision and manifest, school events and community events, student points of view, staff points of view, architectural analysis of the campus and more. All showed a strong community affinity. Looking into a system that combines IB with PBE might affect not only a creation of community around school life and campus but also have an effect on students' feelings, sense of place and sense of belongingness.

community. The first impression may be that the IB is contradictory to the educational perception of PBE, an antithesis to this approach that focuses on local resources, 
place identity and sense of surety. A second, deeper look into these two approaches might indicate something else.

The IB presents on its internet site six basic criteria for realization of the program. They come to facilitate teachers' ability to be flexible and design each teacher's individual way of teaching. Similarly, PBE has six design principles for implementation as described by Gettingsmart ("Guidelines", 2018).

The IB foundations lead to a deeper look into the IB approaches for teaching versus the principles of PBE that inspire to leverage academic outcomes by connecting and engaging with the schools' surrounding communities.

I found that five from the six criteria of both educational methods are similar: both local and global, students are in the center, inquiry, active and collaborative, and interdisciplinarity. The other two principles that do not match might indicate the fundamentals for the difference between these two methods.

\section{IB principles versus PBE principles}

Looking into PBE's first five criteria for education: PBE focuses on local to global context. Understanding local processes and the stages leading to them helps understanding macro processes, from the neighborhood and the school, which are micro, to the world or global process, which is macro. This approach is learner centered, using methods that empower the student, focus on their needs and abilities and boost them. PBE defines its learning as inquiry-based learning; it is a way to understand the world (ecologically, economically, and socio-politically) encouraging curiosity and implementing research methods such as: asking questions and predictions, observing, and collecting data.

PBE encourages a design thinking pedagogical approach, based on experimental methods, that encourages students to be active and impact the community through the school's curriculum. And finally, it emphasizes an interdisciplinary approach that can be taught through project-based learning and that enables the taught curriculum to match adult updates.

In a very similar way but semantically different, the IB approach defines its principles: IB talks about development in local and global contexts, using teaching techniques that rely on real-life examples. It inspires students to connect to real-life contexts and analyze new information through their experiences outside school.The IB approach is defined as designed to remove barriers to learning, using teaching methods that encourage students to set and achieve their personal goals, appreciating cultural and intellectual diversity leading to different individualized learning opportunities. Its learning is described as based on inquiry; students are constantly encouraged and asked to search for information and base their understanding on it. IB is focused on effective teamwork and collaboration; teaching and learning are based on constant interaction and collaboration, students with peers, teachers with colleges and students with teachers.

One of its basic tenets is focused on conceptual understanding. On one hand, this helps to deepen disciplinary understanding as students are encouraged and expected to make new informative connections and put them in new contexts; on the other hand, IB believes in preparing the students to live and work in an interconnected world, so the concepts are taught to integrate knowledge between disciplines. As well seen, the first five criteria of the PBE and IB approaches are almost identical and describe similar teaching perspectives. The two remaining principles that do not match describe a basic element in each one of the educational methods so fundamental that it might define the whole approach.

The last principle of PBE is community as a classroom, which allows parents and

other community members to be part of the ongoing curriculum combined with outdoor activities and out-ofschool experiences. Many would say that this is the core definition and the foundation of what PBE really is.

The last principle of IB is informed by assessment; providing ongoing feedback and measuring the learning process is a crucial part of the IB way of supporting learning and encouraging the students.

\section{Conclusions and Implications}

International Baccalaureate combined with Place Based Education. Staff interviews and text analysis detected another surprising finding regarding the two educational approaches being examined in this research. On a first look at the IB system, taught at an international school as a microcosm of the world, preparing youngsters to act in the real global life with a macro international approach, it seems clear that this educational approach is an antithesis to the educational approach that PBE consists of since PBE focuses on ongoing local, micro, "inhouse" community interaction as part of the curriculum. On a first look at these two approaches, it seems that they are opponents to each other and consist of different educational fundamentals. Surprising as it may be, the findings were different than expected.

Having said that, findings from staff interviews and text analysis showed that IB and PBE have almost identical approaches. Both educational approaches are founded uon six main principles. To my great surprise, I found that five of the six pedagogical principles are identical, while the sixth principle in each approach is what defines the core of the difference between the two.

IB's sixth principle "informed by assessment" focuses on the process of ongoing assessment and the importance of measuring the learning procedure; it highlights a necessity in continuing feedback as a significant part of creating effective learning. PBE's sixth principle "community as a classroom" highlights the basic role the community should 
have in school life and the importance of connecting the curriculum to the human and natural resources surrounding the school.

Even though it is only one principle that differentiates the two approaches, it might just be that it is the most significant principle for each one of them, meaning that the principle of "informed by assessment" and the principle of "community as a classroom" each represent the main core and spin of the respective educational theories they stand for. The fact that only one principle differs between the IB and the PBE approaches highlights how close these approaches really are.

This leads to the conclusion: Based on the information collected in this research, it is possible, and even simple, to integrate a PBE approach as part of the educational concept of the IB system and combine them both under the same pedagogical "roof" by adding the principle of community integration into the school life. The AISB campus life and "open gates" approach shows that when a school allows and invites parents and caretakers to take part in school life as a basic policy and integrates it in the day to day school routine, a fundamental base for community building is created, which eventually leads to creating a sense of place and belongingness of the students towards the school.

\section{Summary}

As seen in this research, nomad families tend to gather around international schools, which makes these schools a good ground for community building. An international school faculty can choose to turn the school into a central and meaningful organization for the expatriates in the host country by creating a social community focused and based on cross cultural people.

Orr discussed the relationship of individuals with their "Place" when having a mobile lifestyle. He described a process of social alienation and ecological degeneracy that affects small communities and ruins them, calling it a "cult of homelessness" (pg.188)

as a part of a global phenomenon of admiration of mobility and ongoing "nomadism". It encourages the individual's alienation and disconnection from social communities and is spreading in large scale (2013). International schools can offer an emotional tool to compete with the "cult of homelessness" phenomenon.

\section{REFERENCES}

Andresen, M., Bergdolt, F., Margenfeld, J., \& Dickmann, M. (2014). Addressing international mobility confusion Developing definitions and differentiations for self-initiated \& assigned expatriates as well as migrants. International Journal of Human Resource Management, 25(16), 22952318. https://doi.org/10.1080/09585192.2013.877058
Based on the field observation and the interviews conducted with school staff members, it was earlier shown that the AISB, a school that bases its curriculum on the IB system, gives at the same time a significant, important role on campus to the community life and integrates the community members in the school's day to day routine. Moreover, this research found that students who are TCKs referred to AISB with a sense of place. These students expressed strong feelings of identification, attachment and dependence toward the school as their place of reference when talking about "sense of place" feelings.

It seems that international education meets place-based theory in a safe place. These two educational approaches are not parallel but overlapping. When looking at this finding, it proves the research assumption that combining IB and PBE contributes to the students creating "Sense of Place" towards the school. Osterman showed that student behavior and human motivation, in general, can be strongly impacted by one's sense of belongingness. It is considered to be a psychological phenomenon with extremely important concepts. This research indicates that students' perceptions about themselves are influenced by the social and emotional environment in school and in class. Quality of student learning and student performance were found to be connected to students feeling motivated and committed to school (2000). This is one way to say that belonging to a group, feeling identified with a group, or having a community to rely on all have a positive effect on students' motivation and commitment.

The main conclusion of this research is that an international school that works with an IB approach and holds a strong affinity to the school community can be described at the same time as a school that works with a PBE approach, looking at the entire world as the "Place" of reference and the international school as its representation.

International schools all over the world are teaching and educating TCKs throughout their nomad lives These schools can affect and support their TCK students' social and emotional needs by encouraging and giving the resources to create a supportive community within the school campus. Therefore, international schools can significantly affect the emotional development of TCKs during their developmental years.

Anton, C., \& Lawrence, C. (2014). Home ls Where the Heart Is: The Effect of Place of Residence on Place Attachment and Community Participation. Journal of Environmental Psychology, $\quad 40, \quad 451-461$. https://doi.org/10.1016/j.jenvp.2014.10.007

Bauman, Z. (1988). Freedom. Stony Stratford: Open University Press. 
Bray, M., \& Yamato, Y. (2003). Comparative education in a microcosm: Methodological insights from the international schools sector in Hong Kong. International Review of Education, 49(1-2), 51-73. https://doi.org/10.1007/978-94007-1094-8_4

Brown, G. G., Reed, P., \& Harris, C. C. (2002). Testing a place-based theory for environmental

evaluation: An Alaskan case study. Applied Geography, 22(1), $\quad 49-76 . \quad$ https://doi.org/10.1016/S01436228(01)00019-4

Cottrell, A. B. (2009, Summer). TCK RESEARCH: A BRIEF LOOK BACK AND AHEAD. TCK Research Network News, 2(2). https://www.researchgate.net/publication/330752212 TCK_RESEARCH_A_BRIEF_LOOK_BACK_AND_AHEAD Cottrell, A. B. (1999, April 11). ATCKs have problems relating to their own ethnic groups. TCK World: The Official Home of Third Culture Kids. http://www.tckworld.com/useem/art4.html

Ezra, R. (2003). Culture, language and personality in the context of the internationally mobile child. Journal of Research in International Education 2(2), 123-149. https://doi.org/10.1177/14752409030022001

Gerner, M. E., Perry, F., Moselle, M. A. \& Archbold, M. (1992). Characteristics of Internationally Mobile Adolescents. Journal of School Psychology, 30(2), 197214. https://doi.org/10.1016/0022-4405(92)90031-Y

Getting Smart. (2017, February 9). What is Place-Based Education and Why Does it Matter?

https://www.gettingsmart.com/2017/02/what-is-placebased-education/

Getting Smart. (2017, March 2). Quick Start Guide to PlaceBased Professional Learning.

https://www.gettingsmart.com/2017/03/place-based-

professional-learning/

Grimshaw, T., \& Sears, C. (2008). 'Where am I from?' 'Where do I belong?' The negotiation and maintenance of identity by international school students. Journal of Research in International Education, 7(3), 259-278. https://doi.org/10.1177/1475240908096483

Halic, O., Bergeron, L., Kuvaeva, A., \& Smith, A. (2015). The International Baccalaureate's Bilingual Diploma: Global trends, pathways, and predictors of attainment. International Journal of Educational Research, 69(1), 59-70. http://dx.doi.org/10.1016/j.jjer.2014.10.004

Hay, R. (1998). Sense of place in developmental context. Journal of Environmental Psychology, 18(1), 5-29. https://doi.org/10.1006/jevp.1997.0060

Hayden, M., \& Thompson, J. (2008). International Schools: Growth and Influence. UNESCO International Institute for Educational Planning.

Hayden, M. (2011). Transnational spaces of education: The growth of the international school sector. Globalisation, Societies and Education, 9(2), 211-224. https://doi.org/10.1080/14767724.2011.577203
International Baccalaureate Organization (IBO). (n.d.). Mission. https://www.ibo.org/about-the-ib/mission/

ICEF Monitor (2014, March 18). New data on international schools suggests continued strong growth. Retrieved March 12, 2015, from https://monitor.icef.com/2014/03/new-dataon-international-schools-suggests-continued-stronggrowth-2/

International Baccalaureate Organization (IBO). (n.d.). The IB Teaching Style.

https://www.ibo.org/benefits/the-ib-teaching-style/ International Schools Consultancy Research (ISC). (2015). About the International Schools Market. https://www.iscresearch.com/about-us/the-market Jorgensen, B., \& Stedman, R. (2006). A comparative analysis of predictors of sense of place dimensions: attachment to, dependence on, and identification with lakeshore properties. Journal of Environmental Management, $\quad 79(3), \quad 316-327$. https://doi.org/10.1016/j.jenvman.2005.08.003

Judson, G. (2016, October 25). Guidelines for Assessment of Place-Based Learning. https://www.gettingsmart.com/2016/10/guidelines-forassessment-of-place-based-learning/

McNeely, C., \& Blanchard, J. (2009). The Teen Years Explained: A Guide to Healthy Adolescent Development. Johns Hopkins University Press.

McNulty, Y., \& Brewster, C. (2017). Theorizing the meaning(s) of 'expatriate': establishing boundary conditions for business expatriates. The International Journal of Human Resource Management, 28(1), 27-61. https://doi.org/10.1080/09585192.2016.1243567

Moore, R. L., \& Graefe, A. R. (1994). Attachments to recreation settings: The case of rail-trail users. Leisure Sciences, $16(1), 17-31$. https://doi.org/10.1080/01490409409513214

Orr, D. (1992, October). Environmental Literacy: Education as if the Earth Mattered. 12th Annual E. F. Schumacher Lectures.

Orr, D. (1992). Place and pedagogy (p.188). In D. Orr, Ecological Literacy: Education and Transition to a Postmodern World (pp. 125-131). State University of New York Press.

Orr, D. (2015, January/February). Lost For Words: A plea for the appreciation of language, literature and the use of wellcrafted words. POWER TO THE PEOPLE, (288), Keynotes. https://www.resurgence.org/magazine/issue288-power-tothe-people.html

Osterman, K. F. (2000). Students' Need for Belonging in the School Community. Review of Educational Research, 70(3), 323-367. https://doi.org/10.3102/00346543070003323

Pollock, D. C., \& Van Reken, R. E. (2009). Third Culture Kids: Growing Up among Worlds (Rev.ed.). Nicholas Brealey Publishing. 
Proshansky, H. M., Fabian, A. K., \& Kaminoff, R. (1983). Place-identity: Physical world socialization of the self. Journal of Environmental Psychology, 39(1), 57-83. https://doi.org/10.1016/S0272-4944(83)80021-8

Schacter, D. L., \& Addis, D. R. (2007). On the constructive simulation of past and future events. Behavioral and Brain Sciences, 30(3), 331-332. https://doi.org/10.1017/S0140525X07002178

Schaetti, B. F. (1993, April 23). The Global Nomad Profile. In The Global Nomad: Benefits and challenges of an Internationally Mobile Childhood. Regents College Conference, London.

Schwartz, S. J., Montgomery, M. J., \& Briones, E. (2006). The role of identity in acculturation among immigrant people: Theoretical propositions, empirical questions, and applied recommendations. Human Development, 49(1), 1-30. https://doi.org/10.1159/000090300

Shamai, S. (1991). Sense of place: an empirical measurement. Geoforum, 22(3), 347-358.

https://doi.org/10.1016/0016-7185(91)90017-K

Sobel, D. (2005). Place-based education: connecting classrooms \& communities (2nd ed.). Great Barrington, MA: Orion Society.

Sylvester, R. (2002). Mapping international education: A historical survey 1893-1944. Journal of Research in
International Education, 1(1), 90-125. https://doi.org/10.1177/147524090211005

Trentelman, C. (2009). Place Attachment and Community Attachment: A Primer Grounded in the Lived Experience of a Community Sociologist. Society and Natural Resources, 22(3), 191-210. https://doi.org/10.1080/08941920802191712

Tulving, E. (1985). Memory and consciousness. Canadian Psychology, 26(1), 1-12.

https://doi.org/10.1037/h0080017

United Nations, Department of Economic and Social Affairs, Population Division (2017). International Migration Report 2017: Highlights (ST/ESA/SER.A/404). https://www.un.org/development/desa/publications/internati onal-migration-report-2017.html

Useem, R. H. (1999, April 11). Third Culture Kids: Focus of Major Study -- TCK "mother" pens history of field. TCK World: The Official Home of Third Culture Kids. http://www.tckworld.com/useem/art1.html

Williams, D.R., \& Roggenbuck, J.W. (1989). Measuring place attachment: Some preliminary results. In Abstracts of the 1989 Symp. on Leisure Research, National Recreation and Park Assoc., Alexandria, VA. 